\title{
A RAZÃO GEOMÉTRICA DA SEPARAÇÃO DE PODERES \\ Juízo Sintético a priori como validação das decisões judiciais com impacto orçamentário
}

Tese de Doutorado

Orientador: Professor Associado Dr. José Maria Arruda de Andrade

\author{
UNIVERSIDADE DE SÃO PAULO \\ FACULDADE DE DIREITO \\ São Paulo - SP




\section{ARGOS MAGNO DE PAULA GREGORIO}

\section{A RAZÃO GEOMÉTRICA DA SEPARAÇÃO DE PODERES \\ Juízo Sintético a priori como validação das decisões judiciais com impacto orçamentário}

Tese apresentada a Banca Examinadora do Programa de Pós-Graduação em Direito, da Faculdade de Direito da Universidade de São Paulo, como exigência parcial para obtenção do título de Doutor em Direito, na área de concentração Direito Econômico e Financeiro, sob a orientação do Professor Associado Dr. José Maria Arruda de Andrade.

UNIVERSIDADE DE SÃO PAULO

FACULDADE DE DIREITO

São Paulo - SP

2017 


\section{Gregorio, Argos Magno de Paula}

A razão geométrica da Separação de Poderes: Juízo sintético a priori como validação das decisões judiciais com impacto orçamentário / Argos Magno de Paula Gregorio: José Maria Arruda de Andrade - São Paulo, 2017.

$169 \mathrm{p}$.

Tese (Doutorado - Programa de Pós-Graduação em Direito Econômico e Financeiro) - Faculdade de Direito, Universidade de São Paulo, 2017.

1. Separação de Poderes. 2. Trias Politica. 3. Decisões Judiciais. 4. Fundamentação. 5. Peça Orçamentária. 6. Impacto Orçamentário. 7. Juízo Sintético a priori. 8 Apriorismo Kantiano. 9. Modelo Geométrico. I. Andrade, José Maria Arruda de, orientador. II. Título. 
Durante meus estudos, perdi meu querido pai e ganhei meu mais que amado filho. É a eles, Sergio e Arthur, a quem dedico este trabalho. 


\section{AGRADECIMENTOS}

Definitivamente este Doutorado se prestou a me ensinar o que já é deveras sabido e muito pouco lembrado: ninguém cresce sozinho; sozinho não se consegue nada.

Se aqui fosse agradecer a todos que me ajudaram, talvez a lista fosse maior que a própria jornada; motivo pelo qual assim o farei de forma resumida, com o pedido de escusas, desde já, aos que vierem injustamente por mim a ser esquecidos.

Ao pequeno Arthur Gregorio, meu amor, minha continuação. Por seu desprendimento ao aceitar, passiva e generosamente, a gravação, em sua história, da Crítica da Razão Pura de Kant como sendo o primeiro livro que lhe foi por seu pai apresentado. Ao meu pai Sérgio, o Gregório, pelas visitas que insiste em me fazer, todas as noites e todos os dias, ainda que em memória. À minha família.

À Faculdade de Direito da Universidade de São Paulo e ao seu inigualável corpo docente. Meus agradecimentos na pessoa do atual Presidente da Comissão de Pós-Graduação, o mais que gentil Professor Fernando Dias Menezes de Almeida; e dos igualmente queridos Rubens Beçak e Mônica Herman.

Ao Departamento de Direito Econômico, Financeiro e Tributário desta velha e sempre nova Academia. Deixando de nomeá-los todos, agradeço àqueles com quem convivi ao longo deste Doutorado e ainda alegremente convivo; por quem nutro carinho, amizade e profunda admiração: Gilberto Bercovici, André Ramos Tavares, José Maria Arruda de Andrade, Luís Fernando Massonetto, Alessandro Octaviani; Heleno Torres, Mauricio Conti, Fernando Scaff; Luís Eduardo Schoueri, Humberto Ávila, Paulo Ayres Barreto e Roberto Quiroga. 
Aos Professores Eduardo Tomasevicius, Enéas de Oliveira Matos, Ignácio Poveda Velasco, Maria Cristina Carmignani; Mauro Penteado, Haroldo Malheiros, Eduardo Munhoz, Elival da Silva Ramos, Roger Leal, Eduardo Bittar, Alysson Mascaro, Samuel Barbosa, Orlando Villas Boas Filho. A extensa lista repercute o muito acima número de créditos que tive o prazer de cumprir. Sou devedor do compartilhamento de suas ideias e conhecimento, direta ou indiretamente aplicados nesta tese.

Aos Professores Alcides Jorge Costa (in memoriam), Eros Grau, Hermes Marcelo Huck, Paulo de Barros Carvalho, Régis de Oliveira, Tércio Sampaio Ferraz: Eternos titulares, sempre inspiração. Aos mestres Alaor Caffé Alves, Edmir Netto de Araújo, Eduardo Bottallo, Gerd Rothmann, Paulo Bonilha e Walter Piva, igualmente inspiradores.

A todos do IBDT, minha casa: meus cumprimentos em nome de seu presidente Ricardo Mariz de Oliveira, amigo tricolor tão inteligente e igualmente querido. À Universidade Presbiteriana Mackenzie, igualmente minha casa: meu agradecimento em nome dos professores José Francisco Siqueira Neto, Felipe Chiarello de Souza Pinto e Eduardo Marcial Ferreira Jardim. À Pontifícia Universidade Católica, aqui nomeando o admirável Roque Carrazza como responsável pela entrega de meu carinho e gratidão por todos.

Meu agradecimento especial à Eloiza (IBDT), Fátima (FDUSP), Eloíde (FDUSP), Mario (FDUSP), Therezinha (PUC) e Miro (Mackenzie): Imensurável o apoio que recebi ao longo de minha vida acadêmica. Sem eles, até o possível seria impossível.

Aos amigos do Tribunal de Impostos e Taxas, meu respeito e admiração. À Teresa Cristina Toledo de Paula, meus sinceros agradecimentos, eis que inspiração aos meus estudos. Aos mais que amigos André Garbuglio, Luis Eduardo de Almeida, Jorge Milburn, Rodrigo Almeida, Gilberto Andrade, agradeço o carinho, a paciência e a honra do sempre alegre convívio. Finalmente, ao meu amigo de todas as horas J. Maria: minha e admiração e gratidão por toda a vida. Não tenho como retribuir tamanha generosidade. Meu muito obrigado!

Ao Senhor Deus, meu Pai: a Ele não cansarei de agradecer. 


\section{RESUMO}

GREGORIO, Argos Magno de Paula. A razão geométrica da Separação dos Poderes: Juízo sintético a priori como validação das decisões judiciais com impacto orçamentário. 2017. 169p. Doutorado - Faculdade de Direito, Universidade de São Paulo, São Paulo, 2017.

Há um duplo-desmando diuturnamente verificado, em conjunto ou em separado, na tradição orçamentária de terrae brasilis: ora se está diante da ausência de previsão daquilo que é necessário à dignidade do ser humano; ora da falta de sua execução, quando ali previsto. O resultado é o distanciamento do orçamento em relação aos seus destinatários finais. A impossibilidade de aproximação entre o orçamento e o povo encontra respaldo, como regra, na desgastada leitura dogmática do Poder Tripartite. Ignora-se o todo em detrimento da incompletude de suas partes. $O$ resultado não pode ser outro, senão a deficitária realização dos anseios do homem junto ao lebenswelt. Diante deste contexto, como resposta e de modo diverso, nossa proposta busca analisar o mecanismo de funcionamento da Trias Politica (sua lógica estrutural, sua composição e, essencialmente a sua finalidade) a fim de que, assim compreendida e sistematicamente observada, possa legitimar a realização prática do orçamento, fazendo-o alcançar suas finalidades essenciais. Não havendo verdade absoluta na ciência, tampouco existindo teoria que se mostre atemporal, buscaremos conclusão no sentido de que seja o artifício da ratio geométrica enquanto juízo sintético a priori para a mais clara compreensão da Separação dos Poderes mais uma ferramenta validadora das decisões judiciais que provoquem impacto orçamentário, dentre as tantas existentes, desde que a essência do Direito seja conservada. Em outras palavras e, em termos práticos, a Trias Politica aqui será vista como sistema de auto-conservação, cujo objeto seja o alcance, a manutenção ou o resgate da essência última do Direito e das instituições (dignidade da pessoa humana) e passará, pois, ao status de juízo sintético a priori nos moldes kantianos, quando e se traduzida em modelo geométrico, ao exemplo da demonstração pretendida neste trabalho. Assim estabelecido, se confirmada esta nova possibilidade de compreensão do Poder enquanto fenômeno sistemático, os reflexos no orçamento dela advirão imediatamente. O modelo apresentado será o primeiro passo para que, entendida em sua essência, a Separação dos Poderes sirva de instrumental eficaz a resgatar, em relação aos anseios do homem, o 
equilíbrio outrora perdido; ou preservá-lo quando diante de iminente ameaça. Contudo, a compreensão deste mesmo modelo se verá limitada a enfrentar a falta de comunicação entre o orçamento e os seus destinatários finais. Simplesmente porque estará impossibilitado de assim fazê-lo enquanto juízo sintético a priori que deverá ser (geral e universal, independente de experimentação). Diante de tal fato, como solução compatível com o mundo da vida, submeteremos a realidade (experiências pontuais e contingenciais) da peça orçamentária ao pensamento de Habermas e nele defenderemos haver encontrado ao menos uma esperança; um segundo passo para a emancipação, ainda distante.

Palavras-chave: 1. Separação de Poderes. 2. Trias Politica. 3. Decisões Judiciais. 4. Fundamentação. 5. Peça Orçamentária. 6. Impacto Orçamentário. 7. Juízo Sintético a priori. 8 Apriorismo Kantiano. 9. Modelo Geométrico. 


\begin{abstract}
GREGORIO, Argos Magno de Paula. The geometric reason of the Separation of Powers: Synthetic Judgment a priori as validation of judicial decisions with budgetary impact. 2017. 169p. PhD thesis, Faculty of Law, University of São Paulo, São Paulo, 2017.
\end{abstract}

There is a double scorn that has been often verified, jointly or separately, in the tradition of the Brazilian budget: sometimes there is a lack of foresight of what is necessary for the dignity of the human being; other times, what is planned does not work. The chasm presents itself as a result between the budget and its final recipients. The impossibility of approaching the budget and the people is supported, as a rule, in the worn dogmatic reading of Tripartite Power. The whole is ignored to the detriment of the incompleteness of its parts. The result can be only a deficit in the realization of man's life's desires. Given this context, in response and in a different way, our proposal seeks the mechanism of operation of Trias Politica (its structural logic, composition and, its purpose essentially), which may legitimize the practical realization of the public budget, making it achieve its essential purposes. If there is no absolute truth in science, and if there is no theory that is timeless, we will seek to conclude that the artifice of the geometric relationship is a synthetic a priori judgment. We will seek a clearer understanding of the separation of powers through this validating tool for judicial decisions with budgetary impact. This will only be achieved as long as the essence of law is retained. In other words and in practical terms, Trias Politica will be a system of self-preservation, an object of reaching, maintaining or reviewing the last word of Law and its institutions (dignity of the human person) and will be Considered a priori Synthetic Judgment in the Kantian molds, when and only in the hypothesis of being translated as a geometric model, as we intend to demonstrate in this research. Thus established, if this new process of understanding is confirmed as a systematic phenomenon, its reflexes will automatically perceived at the public budget. The model should be the first step to be really understood. The Separation of Powers should serve as an effective instrument for rescuing the lost balance in relation to man's yearnings; or preserve it in the face of imminent threat. However, the understanding of this model will be limited by the lack of communication between the public budget and its final 
beneficiaries. Simply because it is incapable of assimilating it as a synthetic prior judgment which must be general and universal, independent of experimentation. Faced with this reality, as a solution compatible with the world of life, we will submit the reality of the public budget to the Habermas thought. This will be our second step to Emancipation that still remains far away.

Keywords: 1. Separation of Powers. 2. Trias Politica. 3. Judicial decisions. 4. Grounds. 5. Public budget. 6. Budgetary impact. 7. Synthetic Judgment a priori. 8 Kantian apriorism. 9. Geometric model. 


\section{RIASSUNTO}

GREGORIO, Argos Magno de Paula. II modello geometrico della separazione dei poteri: giudizi sintetici a priori per convalidare le decisioni giudiziarie che influiscono negativamente i conti pubblici. 169p. 2017. Tesi di dottorato presso la Facoltà di Giurisprudenza dell'Università di San Paolo, San Paolo nel 2017.

Un doppio disprezzo si verifica spesso insieme o separatamente nel bilancio del Brasile: a volte vi è una mancanza di visione su ciò che è necessario per la dignità umana; Altre volte, le previsioni non sono confermate. I risultati non permettono la realizzazione dei desideri della società. Questa pratica si basa sull'interpretazione dogmatica della separazione dei poteri. L'insieme viene ignorato a scapito della incompletezza delle sue parti. II risultato non può che essere un deficit nel raggiungimento i desideri della vita umana. In questo contesto, in risposta, e in un modo diverso, la nostra proposta è quello di studiare il meccanismo di funzionamento della "Trias Politica" (la sua struttura logica, la composizione e lo scopo, essenzialmente) che possono legittimare il bilancio del governo per raggiungere $\mathrm{i}$ suoi obiettivi principali. Se non esiste una verità assoluta nella scienza, e non c'è nessuna teoria che è senza tempo, possiamo concludere che la relazione geometrica del dispositivo è un giudizio sintetico a priori. Avremo una chiara comprensione della separazione dei poteri attraverso questo strumento per convalidare le decisioni giudiziarie che hanno implicazioni di bilancio. Questo sarà possibile solo finché l'essenza del diritto viene mantenuta. In altre parole, in termini pratici, Trias Politica sarà un sistema di auto-conservazione, un oggetto di raggiungere, mantenere o rivedere l'ultima parola della legge e delle sue istituzioni (la dignità della persona umana) e saranno considerati a priori giudizio sintetico negli stampi kantiane, quando e solo nell'ipotesi di essere tradotto come un modello geometrico, come noi intendiamo dimostrare in questa ricerca. Così stabilito, se questo nuovo processo di comprensione si conferma come un fenomeno sistematico, le sue conseguenze saranno percepiti automaticamente dal bilancio pubblico. II modello dovrebbe essere il primo passo per essere veramente capito. La separazione dei poteri dovrebbe servire come uno strumento efficace per recuperare l'equilibrio perduto; o proteggere gli uomini di una minaccia imminente. Tuttavia, la comprensione di questo modello è limitata dalla mancanza di comunicazione tra il bilancio del governo e beneficiari finali. Semplicemente perché non è in grado di assimilare come un giudizio sintetico "a priori" per essere generale e universale. Data questa realtà, come una soluzione compatibile con il mondo della vita, II bilancio sarà visto attraverso gli occhi di Habermas. Questo sarà il nostro secondo passo verso l'emancipazione, che è ancora lontano.

Parole chiave: 1. Separazione dei poteri. 2. "Trias Politica". 3. Le decisioni giudiziarie. 4. Motivi. 5. Bilancio pubblico. 6. Impatto di bilancio. 7. Giudizio sintetico a priori. 8. Apriorismo kantiano. 9. Modello geometrico. 


\section{SUMÁRIO}

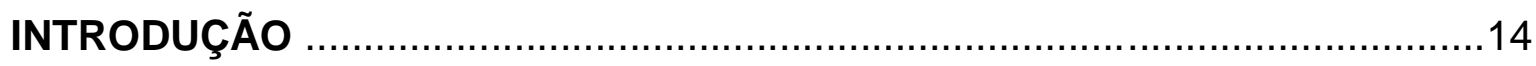

\section{PARTE I - DA ESSÊNCIA}

I.1. Da essência da Essência ...............................................................19

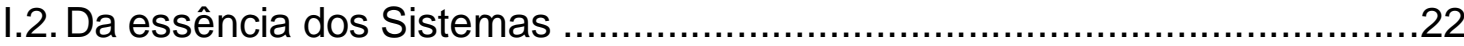

I.3. Da essência do Direito .......................................................................... 33

I.4. Da essência do Direito Financeiro e do Orçamento ..................................42

I.5. Da essência do Juízo Sintético a priori em Kant ....................................52

I.6. Da essência da Trias Política ou Teoria da Separação dos Poderes .........61

I.7. Da essência dos Modelos Geométricos .........................................77

\section{PARTE II - DA CONFRONTAÇÃO E DA REFUTABILIDADE}

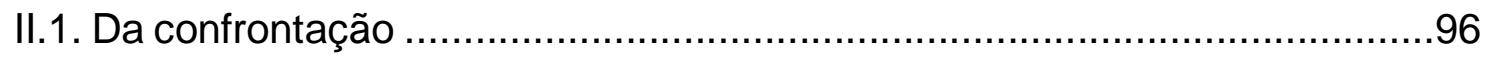

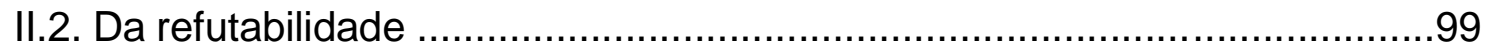

\section{PARTE III - DA EXPERIMENTAÇÃO}

III.1. Da experimentação prática (Modelo Geométrico) ................................112

III.2. Da experimentação teórica (ou da Pós-Experimentação) ......................131

PARTE IV - DAS CONCLUSÕES 


\section{INTRODUÇÃO}

A presente Tese tem por objetivo demonstrar que a geometrização do Princípio da Separação dos Poderes pode servir de fundamentação à exata compreensão da extensão e alcance deste verdadeiro dogma dos regimes democráticos modernos, de modo a esclarecer os seus limites, seus alcances e a real sistemática de seu funcionamento.

Segundo a premissa do "todo indecomponível", buscaremos provar que, enquanto juízo sintético a priori, nos moldes Kantianos, tal representação Euclidiana terá aplicação prática e Universal, justificando a tomada de decisões pelos Poderes e, ao mesmo tempo, desconstruindo a tese da inaceitável interferência de um sobre o outro.

Tomaremos por base a funcionalidade e o proto-utilitarismo do kantiano, ainda que o mesmo não seja assim classificado. Importante frisar que nossa exposição será tecida sob o manto da dualidade autopreservação-desnaturação, com destaque às consequências derivadas da inobservância da lógica de funcionamento de um sistema ou de parte dele (ao exemplo do que ocorre com o Direito como um todo; e da Separação dos Poderes, enquanto parte).

Por outro lado, diante da sua observância (da lógica sistemática aqui proposta), buscaremos, com os mesmos esforços, dimensionar o real abismo entre as opções feitas pelos políticos e as necessidades de seus destinatários últimos, assim o fazendo sob a ótica orçamentária. 
Em relação ao Direito, pretendemos analisá-lo sob duas perspectivas diversas, quais sejam, (i) enquanto sistema seletivamente permeável e (ii) enquanto objeto cultural da vida exterior e relacional dos homens.

Pela primeira perspectiva, buscaremos demonstrar que essa permeabilidade seletiva que lhe é afeta torna obrigatória a observância de suas regras internas de funcionamento (dinâmica estrutural) sem, contudo, impedir que aquelas que levem à desnaturação de sua essência sejam dele excluídas ou contingencialmente escanteadas.

Pela segunda perspectiva, enfrentaremos o desafio de desconstruir lógica, geométrica e sistematicamente o confortável discurso acerca da proibição do ativismo de qualquer dos agentes de poder, o qual tem por alicerce o já insustentável, falacioso e medieval dogma da separação dos poderes. Buscar-seá, para tanto, evidenciar as suas razões (assim como as do Direito), as finalidades de sua criação e manutenção (da separação dos poderes) e a realização de sua essência (através da execução do orçamento).

Finalmente, serão por nós reconhecidos como atentado à própria autopreservação da Trias Política cada instante em que se despreza o todo em detrimento da percepção incompleta baseada em suas partes, onde, na escolha entre a sua verdadeira realização e o conforto dogmático, opta-se por este último, desnaturando por completo o próprio Direito.

A evolução de nosso pensamento encontrará gênese na análise da essência (enquanto exercício de compreensão do processo da própria experiência), deslocando-se, sob tal perspectiva, (i) à essência dos Sistemas, (ii) à essência do Direito, (iii) à essência do Direito Financeiro e do orçamento, (iv) à essência do juízo sintético a priori em Kant. 
Na sequência, o pensamento Revolucionário Francês será visitado quando do exame da (v) essência da Trias Politica. Nesse instante, dar-se-á especial destaque ao labor de Montesquieu, que desde já afirmamos ter desvirtuado o trabalho de Locke, sob influência de Sieyes diante da necessidade contingencial da Revolução.

Este descompasso se refletirá em praticamente todos os Estados Democráticos Modernos, na medida em que determinou a "nova" e "inventiva" forma de repartição independente de poderes em detrimento do original compartilhamento e interdependência referido por Locke.

Moto contínuo, buscaremos evidenciar que a lógica da busca pelo pronunciamento do Judiciário se confunde com a ideia de autopreservação, com o resgate do fim último do próprio Direito, qual seja, a obtenção, a preservação ou o resgate da dignidade da pessoa humana, verdadeira forma de felicidade pessoal e concreta, a despeito de sua subjetividade.

Finalmente, ao enfrentarmos (vi) a essência dos Modelos Geométricos, nos será permitido compreender a sistemática e geométrica aplicação do princípio da separação dos poderes enquanto juízo sintético a priori, trazendo a perspectiva da chamada virada Kantiana (Kantische Wende) à peça orçamentária.

Sob esse tecido, em segunda parte faremos a confrontação e a refutabilidade de nossos argumentos em capítulo próprio; não dos afetos à mecânica de funcionamento da Trias Politica mas, ao revés, daqueles destinados, de um lado, à comprovação da eficiência da macroperspectiva (sob a ótica kantiana) por nós aqui proposta; de outro, a negar a linearidade tão comumente dedicada ao estudo dos sistemas sociais dinâmicos, em nome da análise mais profunda de seu comportamento. 
Em sede de confrontação testaremos o modelo geométrico que outrora foi apresentado especialmente na questão relativa à sua mecânica de funcionamento enquanto sistema, com o objetivo primeiro de verificar se a solução proposta guarda relação de coerência estrutural que lhe é afeta e se a sua inobservância resulta em sua desnaturação.

Em continuidade, admitida a prestabilidade de nosso modelo, buscaremos a sua aplicação à realidade sistêmica, complexa e legaliforme, nos moldes a serem externados quando de sua enunciação. É nesse momento que se dará (assim deve ser) a integração das ciências naturais (modelos matemáticos geométricos) e as sociais (o Direito, especialmente o fenômeno da Separação dos Poderes e os seus efeitos junto ao orçamento).

Entendido o Direito enquanto meio - e não fim - os resultados do exercício demonstrativo ao qual nos referimos deverá se mostrar como elemento de autopreservação de sua essência; e, em última instância, aproximar a realidade de seu fim.

Por último, os resultados poderão ser aplicados a qualquer caso in concreto, acaso o modelo aqui ventilado sirva realmente como instrumental para o alcance do objetivo último do Direito, através da concretização da peça orçamentária.

Mas nossas atenções não serão voltadas apenas aos resultados. A verificação da eficiência de nossa ganhará corpo quando as premissas que servirão a priori de fundamento de nosso modelo atingirem a dinâmica do funcionamento da Separação dos Poderes como um todo, e não deste ou daquele "Poder" individualmente. Nosso objetivo é fazer com que a percepção intuitiva se sobreponha às conceituações, como assim devem ser os juízos sintéticos a priori. 
Já em relação à refutabilidade, nossos esforços serão dirigidos aos obstáculos que evidentemente serão em nosso caminho colocados, como usualmente assim o fazem os adeptos do dogmatismo. São eles: (i) o ativismo judicial, (ii) a reserva do possível e os limites orçamentários e, (iii) o risco da superposição dos Sistemas do Direito e da Política.

Pretendemos realizar então a falseabilidade das consequências advindas da hipótese de funcionamento de tal modelo; não do modelo em si, acaso o mesmo se demonstre eficiente e válido. Pela dinâmica do método hipotético-dedutivo: sendo nossas hipóteses verdadeiras, suas conjecturas também assim o serão.

Nosso objetivo se completará, para as posteriores e imediatas conclusões, com a experimentação em sua dupla manifestação: prática, em relação ao modelo geométrico proposto; teórica (enquanto pós-experimentação) em relação a um possível segundo passo, qual seja, uma nova contextualização para a elaboração do orçamento.

Para tanto, adotaremos a plausibilidade da Teoria da Ação Comunicativa de Habermas como meio a possibilitar o real diálogo entre a peça orçamentária e os anseios do mundo da vida de seu destinatário último, o povo. 


\section{PARTE I - DA ESSÊNCIA}

\section{I.1. DA ESSÊNCIA DA ESSÊNCIA}

Segundo o físico dinamarquês Niels Bohr, "nenhum fenômeno é fenômeno até ser observado". É nesse sentido que se busca aqui a compreensão dos fenômenos, compreensão esta circunscrita, verbi gratia, não ao Direito como um todo, mas especialmente ao fenômeno da Trias Política, objeto este por muitos considerado afeto à Ciência Política1. De antemão, reste consignado que a observação pretendida dar-se-á tendo por foco a essência do fenômeno-objeto "Separação dos Poderes".

Evidenciada a opção adotada, direto aos seus desdobramentos: se nossa matriz é assumidamente kantiana, não faria sentido qualquer esforço que não se identificasse com a tentativa de apreender a experiência, ou seja, da preocupação em compreender o processo da própria experiência. O primeiro resultado óbvio é o descarte, pois, da ideia de essência enquanto eidos, dado que o desafio assumido é justamente a construção de um modelo que se evidencie universal e necessário, capaz de desvendar, a priori², o essencial de seu funcionamento (deste modelo) e o objeto que ele visa projetar.

\footnotetext{
${ }^{1}$ Cite-se: REALE, Miguel. Teoria do Direito e do Estado, 2a Ed. Ed. Martins, São Paulo, 1960; JELLINEK, Georg, Teoria General del Estado, Ed. Albatroz, Buenos Aires, 1954; KELSEN, Hans, Teoria General del Estado, Ed. Nacional, México, 1959; BONAVIDES, Paulo, Ciência Política, 9²Ed. Rio de Janeiro: Ed. Forense, 1993; DORIA, Sampaio, Direito Constitucional - Teoria Geral do Estado, vol. I, tomo II, 5a ed. Max Limonad; THEIMER, Walter. Historia de las Ideas Politicas. Ed. Ariel, 1960; CONSTANT, Benjamin, Escritos de Política, São Paulo, Martins Fontes, 2005; KELSEN, Hans. Teoria Pura del Derecho, Eudeba, Buenos Aires, 1960; BURDEAU, Georges, L'Etat, Ed. Du Seuil, Paris, 1970; STOPPINO, Mario. Potere Politico e Stato, Ed. Giuffrè, Milão, 1968.

2 Como já advertiu Miguel REALE [2009:108], o a priori kantista não equivale a "inato", nem tampouco significa algo que preceda no tempo à experiência. Corresponde, antes, ao que é independente da experiência individual. Representa, ao mesmo tempo, a forma legal ou constitutiva da experiência mesma, pois é a consciência cognoscente (considerada universalmente, e não como consciência deste ou daquele outro indivíduo) que, segundo Kant, cria de certa forma os objetos, segundo leis que the são anteriores e próprias, ordenando o mundo disperso ou informe das sensações "recebidas" segundo as formas do espaço e do tempo, e os enlaces das "categorias".
} 
Já da leitura rasa do consagrado "Crítica da Razão Pura", especialmente em seu Prefácio à Segunda Edição (1787) nos é permitido afirmar que para KANT [2008:16] a constituição dos fenômenos no mundo se dá através do modo pelo qual os experimentamos, restando descartada de plano (nossa segunda e necessária delimitação) a ideia de compreender a essência das coisas-em-si (das Ding na sich). Assim anunciado, assim o faremos ${ }^{3}$.

Adotado o desafio de se compreender o processo da experiência (compreensão a priori), parece-nos correto afirmar que o objeto eleito, qual seja, o phainomenon (do grego, observável) da Trias Politica, só pode ser verdadeiramente conhecido quando e se observado sob a macroperspectiva (Princípio da Perspectiva em Kant) advinda de um modelo de envergadura universal que o revele.

Que fique claro: O impacto de sua aparente redução sistêmica será, em verdade, expansão do modo de sua compreensão, especialmente em relação ao seu mecanismo de funcionamento. Será, pois, elemento descortinador de sua essência. Essência esta que, per se, volta-se ao ser humano e, em último plano, à sua dignidade.

Se nos perguntássemos qual o porquê do Direito, o porquê de sua sistematização, o porquê da criação de modelos geométricos/matemáticos, o porquê de sua catalogação (dos modelos geométricos) enquanto juízos sintéticos a priori sob a perspectiva kantiana e, finalmente, o porquê de sua prestabilidade enquanto validador de decisões judiciais com impacto orçamentário, a resposta seria única: para a preservação/recuperação do inegociável e absoluto valor da dignidade humana ${ }^{4}$. Esta é ao menos a pretensão que se pretende demonstrar.

\footnotetext{
${ }^{3}$ Ainda que trate do imperativo categórico (e não especificamente do juízo sintético a priori), é preciosa a ponderação de GRANATO, Marcelo [2014:631], ao afirmar que "segundo Kant, o ser racional "quer necessariamente que todas as faculdades sejam desenvolvidas nele, porque lhe são úteis e estão dadas para toda espécie de fins possíveis".

${ }^{4}$ Consoante o mesmo autor, em relação à dignidade humana, destacamos, verbis: "Esse valor absoluto que Kant atribui ao ser humano constitui a sua dignidade. Como um fim em si mesmo, ele não pode ser comparado, substituído, compensado por outra coisa. Não pode ser mensurado,
} 
Mais que oportuna a advertência que aqui fazemos: A sugestão capitulada em negrito pode levar o leitor a acreditar estar diante de evidente contradição, diante de premissa absolutamente contrária ao pensamento kantiano. Todavia, a evidência não só cai por terra como também se desfaz imediatamente se e quando confrontada com nossas delimitações expostas nos parágrafos precedentes. Que seja definitivamente gravado em pedra que a essência aqui versada é e será a essência kantiana, derivada do inatismo cartesiano e do empirismo de HUME.

Essência esta que, per se, traduz-se como conteúdo do conhecimento, como seu processo de síntese pelo sujeito que de modo estrutural the é inatamente conhecedor, fruto da organização, análise, catalogação e sistematização de informações sensíveis aos sentidos. Para tanto, o amparo necessário nos será dado pela Teoria Geral dos Sistemas, pela Matemática e especialmente pela Geometria Euclidiana (tal qual se utilizou Kant em sua Crítica à Razão Pura), cuja observações são revestidas do apriorismo que entendemos indispensável.

precificado, trocado: "o que tem preço, em seu lugar também se pode pôr outra coisa, enquanto equivalente; mas o que se eleva acima de todo preço, não permitindo, portanto, qualquer equivalente, tem uma dignidade". O ser humano não tem um valor relativo, mas íntimo; assim, não tem preço, mas dignidade; é pessoa, não coisa. 


\section{IV - DAS CONCLUSÕES}

A despeito do distanciamento do orçamento em relação aos seus destinatários finais, a leitura dogmática do Poder Tripartite insiste em ignorar o todo em detrimento da incompletude de suas partes.

Neste trabalho, buscamos a análise do mecanismo de funcionamento da Trias Politica no vezo de que esta pudesse legitimar a realização prática do orçamento, fazendo-o alcançar suas finalidades essenciais. Sob o ponto de vista sistemático e metodológico, ousamos dizer que nosso mister foi devidamente alcançado.

Fixadas nossas premissas iniciais (essência), ao partirmos para a confrontação e a falseabilidade de suas consequências, concluímos que 0 artifício da ratio geométrica enquanto juízo sintético a priori para a mais clara compreensão da Separação dos Poderes é, até segunda ordem, ferramenta validadora das decisões judiciais que provoquem impacto orçamentário, dentre as tantas existentes. A condição sine qua non, para tanto é apenas a manutenção da essência do Direito.

Traduzida em modelo geométrico, a mecânica de funcionamento da Trias Politica passa, pois, ao status de juízo sintético a priori nos moldes kantianos. E essa passagem implicará em reflexos imediatos no orçamento. $O$ modelo aqui apresentado serve de primeiro passo para que a Separação dos Poderes sirva de instrumental eficaz a resgatar ou preservar o homem do desequilíbrio ao qual se submete no mundo da vida. , em relação aos anseios do homem, o equilíbrio outrora perdido ou preservá-lo

Sabendo que a compreensão de nosso modelo não se presta a combater a falta de comunicação da peça orçamentária com os seus destinatários finais, submetemos a realidade (experiências pontuais e contingenciais) desta última ao pensamento habermasiano, entendendo termos encontrado uma esperança para um segundo passo em direção à verdadeira Emancipação. 


\section{REFERÊNCIAS BIBLIOGRÁFICAS}

ABBAGNANO, Nicola. Dicionário de Filosofia. 4를. São Paulo: Martins Fontes, 2000.

ABRANCHES, Sérgio H. H. de. Presidencialismo de Coalizão: O Dilema Institucional Brasileiro. Dados, vol. 31, № 1. 1988.

ADAMS, George Burton. The origin of the English Constitution. Washington D.C: BeardBooks,2002.

ADEODATO, Alberto. Manual de Ciência das Finanças. 3를. São Paulo: Saraiva, 1949.

ADEODATO, João Maurício. Filosofia do Direito. 4ª Ed. São Paulo: Saraiva, 2009.

BITTAR, Eduardo C. B. (Org.). Filosofia e Teoria Geral do Direito. 1를. São Paulo: Quartier Latin, 2011.

ADORNO \& HORKHEIMER. Dialética do Esclarecimento. $1^{\text {a }}$ Reimpressão. Rio de Janeiro: Jorge Zahar Editor, 2006.

ALMEIDA MELLO, Leonel Itaussu. Clássicos da Política, v.1, organizado por Francisco C. Weffort. São Paulo: Ática, 2001. 
ALVES, Alaôr Caffé. Dialética e direito: linguagem, sentido e realidade: fundamentos a uma teoria crítica da interpretação do direito. Barueri: Manole, 2010.

ALVES, Francisco de Assis. Constituições do Brasil. 1ª Ed. Brasília-DF: Ed. IASP, 1985.

AMARAL, Gustavo. Interpretação dos direitos fundamentais e o conflito entre poderes. Teoria dos Direitos Fundamentais. Rio de Janeiro: Renovar, 2001. p.116.

AMARAL FELIPE, Cleber Vinicius do. Reta razão aplicada ao agir: apropriações da virtude ético-política da prudência. História da Historiografia. V.9. Ouro Preto: UNICAMP, 2012.

ANDRADE, José Maria Arruda de. A Constituição Brasileira e as Considerações Teleológicas na Hermenêutica Constitucional. In: SOUZA NETO, Cláudio P. de; SARMENTO, Daniel; BINEMBOJM, Gustavo. Vinte anos da Constituição Federal de 1988. Rio de Janeiro: Editora Lumem Juris, 2009.

ANDRADE, José Maria Arruda de. Economicização do Direito Concorrencial. 1 ${ }^{a} E d$. São Paulo: Quartier Latin, 2014. Interpretação da Norma Tributária. $1^{\underline{a} E}$ d. São Paulo: MP Editora, 2006.

ARECCHI, F.T. Caos e complessità nel vivente, IUSS Press, Pavia, 2004.

ARISTOTELES. A Política. 1를. Bauru: Edipro, 1995. 
Metafísica. Tradução, textos adicionais e notas Edson Bini.

Bauru: Edipro, 2006.

ASSONI FILHO, Sérgio. Transparência Fiscal e democracia. Porto Alegre: Núria Fabris, 2009.

ATIENZA, Manuel. As razões do Direito (Teorias da Argumentação Jurídica). $3^{a}$ Ed. São Paulo: Landy Editora, 2006.

ÁVILA, Humberto. Segurança Jurídica. 1르. Ed. São Paulo: Malheiros, 2011. Sistema Constitucional Tributário. 3ªEd. São Paulo: Saraiva, 2008.

AZAMBUJA, Darcy. Introdução à Ciência Política. 3ªEd. Porto Alegre: Ed. Globo, 1979.

BACON, Francis. Ensaios Sobre Moral e Política. 1ªEd. São Paulo: Edipro, 2001.

BALEEIRO, Aliomar. Uma introdução à Ciência das Finanças. Atualizado por Hugo de Brito Machado Segundo. 17ª Ed. Rio de Janeiro: Forense, 2010.

BARROSO, Luís Roberto. Curso de Direito Constitucional Contemporâneo. $1^{\underline{a}} \mathrm{E} d$. São Paulo: Ed. Saraiva, 2009. 
Judicialização, Ativismo Judicial e Legitimidade Democrática. Revista Atualidades Jurídicas - Revista Eletrônica do Conselho Federal da OAB. Ed. 4. Janeiro/Fevereiro 2009.

BASTOS, Celso Ribeiro. Elementos de Direito Constitucional. 2ªEd. São Paulo: EDUC. Edição Saraiva, 1976.

BEÇAK, Rubens. A hipertrofia do executivo brasileiro: impacto da Constituição de 1988. Campinas: Millennium, 2008.

BERCOVICl, Gilberto. Dilemas do Estado Federal Brasileiro. 1를 Ed. Porto Alegre: Livraria do Advogado, 2004.

BERCOVICl, Gillberto. MASSONETTO, Luís Fernando. A Constituição dirigente invertida: a blindagem da Constituição Financeira e a agonia da Constituição Econômica. In: Boletim de Ciências Econômicas. Vol. XLIX. Coimbra: 2006.

BERTALANFFY, Ludwig von. Teoria General de los Sistemas. $10^{\stackrel{a}{ }}$ ed. México: FCE, 1995

BITTAR, Eduardo C.B., ALMEIDA, Guilherme Assis de. Curso de Filosofia do Direito. 5ª̊d. São Paulo: Atlas, 2007.

BOBBIO, Norberto. A Era dos Direitos. $6^{\underline{a}}$ Tiragem. Rio de Janeiro: Campus Elsevier, 2004.

Direito e Estado no Pensamento de Emannuel Kant. 4ª Ed. Brasília: UNB, 1997. 
- Teoria do Ordenamento Jurídico. 9ªd. Brasília: Ed. Universidade de Brasília, 1997.

BONAVIDES, Paulo. ANDRADE, Paes. História Constitucional do Brasil. 1ª̂Ed. Brasília: Ed. Paz e Terra Política, 1989.

BONAVIDES, Paulo. Ciência Política. 9ªEd. Rio de Janeiro: Ed. Forense, 1993. Teoria Constitucional da Democracia Participativa. $3^{a}$ Ed. São Paulo: Malheiros, 2008.

BORGES, José Souto Maior. Ciência Feliz. 3ª̣Ed. São Paulo: Quartier Latin, 2007.

BULOS, Uadi Lammêgo. Curso de Direito Constitucional. 4a Edição. São Paulo: Saraiva, 2009.

BUNGE, Mario. Diccionario de filosofía. 3. ed. Buenos Aires: Siglo XXI, 2005.

CAMPANHOLE, Adriano; CAMPANHOLE, Hilton Lobo. Constituições do Brasil. 13.ed. São Paulo: Atlas, 1999.

CANOTILHO, J. J. Gomes. Tomemos a sério o silêncio dos poderes públicos - o direito à emanação de normas jurídicas e à proteção judicial contra as omissões normativas, in: TEIXEIRA, Sálvio de Figueiredo (org.). As garantias do cidadão na justiça. São Paulo: Saraiva, 1993. 
. Direito Constitucional e Teoria da Constituição. $7^{7}$ Ed. Coimbra:

Almedina, 2008.

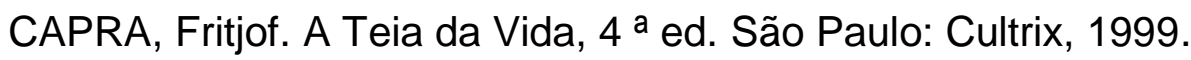

CARNELUTTI, Francesco. Metodologia do Direito. 1를. Campinas: Bookseller, 2000.

Arte do Direito. 1ªEd. Campinas: Russell, 2006.

CARRILHO, Cristiano. Manual de História dos Sistemas Jurídicos. 1ªEd. Rio de Janeiro: Campus Jurídico, 2009.

CARSON, Emily. Kant on the Method of Mathematics. Journal of the History of Philosophy, 1999.

CARVALHO, Paulo de Barros. Derivação e positivação no direito tributário. v.1. São Paulo: Noeses, 2011.

CAVALCANTI, Teófilo.(Org.) Estudos em Homenagem a Miguel Reale. São Paulo: Revista dos Tribunais, Ed. Da Universidade de São Paulo, 1977.

CHADWICK, H. M., Studies on Anglo-Saxon Institutions(Cambridge, 1905).

CHAUÍ, Marilena. Introdução à História da Filosofia: dos Pré-Socráticos a Aristóteles. Volume I. 2. ed. São Paulo: Companhia das Letras, 2002 
COBBETT, Guilherme. História da Reforma Protestante em Inglaterra e Irlanda. Traduzida do Inglês. Lisboa: Tipografia de Bulhões, 1827.

COMMAILLE, Jacques. KALUSZYNSKI, Martine. La Fonction Politique de La Justice. Collection Recherché. Paris: Editions La Decouverte, 2007.

CONSTANT, Benjamin. Escritos de Política. 1ªEd. São Paulo: Martins Fontes, 2005.

CONTI, José Mauricio. A Autonomia Financeira do Poder Judiciário. 1를 Ed. São Paulo: MP Editora, 2006.

CONTI, José Mauricio (coord.). Orçamentos Públicos. A Lei 4.320/1964 Comentada. 3ªEd. São Paulo: Revista dos Tribunais, 2014.

CONTI, José Mauricio. SCAFF, Fernando Facury (coord.). Orçamentos Públicos e Direito Financeiro. 1 ${ }^{1}$ Ed. São Paulo: Revista dos Tribunais, 2011.

CUNHA JUNIOR, Dirley. A Efetividade dos Direitos Fundamentais Sociais e a Reserva do Possível. In: CAMARGO, Marcelo Novelino. Leituras Complementares de Direito Constitucional. Salvador: Juspodivm, 2006.

DALLARI, Dalmo de Abreu. Elementos de Teoria Geral do Estado. 19ªEd. São Paulo: Saraiva, 1995. 
DERBLI, Felipe. O princípio da proibição de retrocesso social na Constituição de 1988. Rio de Janeiro: Renovar, 2007.

DINIZ, Maria Helena. A Ciência Jurídica. 3ªEd. São Paulo: Saraiva, 1995.

As lacunas no Direito. São Paulo: Revista dos Tribunais, 1981.

DORIA, Sampaio. Direito Constitucional - Teoria Geral do Estado. V1, Tomo 1. 5ª̂d. São Paulo: Max Limonad,

. Direito Constitucional - Teoria Geral do Estado. V.1, Tomo 2. 5ª̂d. São Paulo: Max Limonad,

DURANT, Will. Filosofia da Vida. 8ªEd. São Paulo: Companhia Editora Nacional, 1951.

EUCLIDES. Os Elementos. 1ํㅡㄹ. São Paulo: Ed. UNESP, 2009.

FERRAZ JÚNIOR, Tércio Sampaio. A Ciência do Direito. 1르d. São Paulo: Atlas, 1977. . Teoria da Norma Jurídica. 4ªEd. Rio de Janeiro: Forense, 2005.

FERREIRA FILHO, Manoel Gonçalves. Curso de Direito Constitucional. 35르. São Paulo: Ed. Saraiva, 2009. 
FRANÇA, Rubens Limongi. Formas e Aplicação do Direito Positivo. São Paulo: Revista dos Tribunais, 1969

GALILEI, Galileu. Diálogo sobre os Dois Máximos Sistemas do Mundo Ptolomaico e Copernicano. 1를. São Paulo: Editora 34, 2011.

GARCIA-PELAYO, Manuel. As Transformações do Estado Contemporâneo. 1 1ª Ed. Rio de Janeiro: GEN Forense, 2009.

GIANNETTI, Eduardo. Felicidade. 12 $2^{\underline{a}}$ Reimpressão. São Paulo: Companhia das Letras, 2012.

GOMES CANOTILHO, José Joaquim. Direito Constitucional e Teoria da Constituição. Coimbra: Almedina, 1999.

GRANATO, Marcelo de Azevedo. Quem habita a dignidade humana? A fundamentação kantiana. In. Revista da Faculdade de Direito da Universidade de São Paulo, v.109. São Paulo, 2014.

GRAU, Eros Roberto. Ensaio e Discurso sobre a Interpretação/ Aplicação do Direito. 5ªEd. São Paulo: Malheiros, 2009.

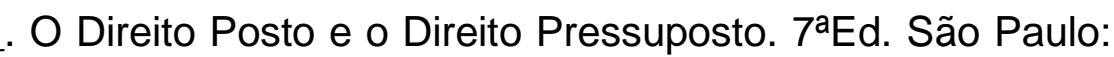
Malheiros, 2008.

GREGORIO, Argos. A Capacidade Contributiva. 1ªEd. São Paulo: Quartier Latin, 2011. 
habermas, JÜRGEN. Pensamento Pós Metafísico. Estudos Filosóficos. 2ª̣Ed. Rio de Janeiro: Tempo Brasileiro, 2002.

HAMILTON, Alexander; JAY, John; MADISON, James. O Federalista. In: Os Pensadores. São Paulo: Victor Civita Editor, 1979.

HART, H.L.A. Ensaios sobre Teoria e Filosofia do Direito. São Paulo: Elsevier, 2009.

. O Conceito de Direito. Lisboa: Fundação Calouste Gulbekian, 1986.

HAURIOU, André. Derecho Constitucional e Instituciones Politicas. 4"a Ed. Barcelona: Editora Ariel, 1971.

HAURIOU, Maurice. Principios de Derecho Publico y Constitucional. 2ªEd. Madrid: Instituto Editorial Reus,

HEGENBERG, Leônidas. Lógica Simbólica. São Paulo: Herder, 1966.

HEIDEGGER, Martin. História da Filosofia de Tomás de Aquino a Kant. Petrópolis: Vozes, 2009.

HOBBES, Thomas. Os Elementos da Lei Natural e Política. 1를. São Paulo: Ed. Ícone, 2003. 
HORKHEIMER, Max. Eclipse da Razão. Rio de Janeiro: Editorial Labor do Brasil, 1976.

HUME, David. Tratado da Natureza Humana. 1ํㅡㄹ. São Paulo: Editora UNESP, 2000.

JACQUES, Paulino. Do Conceito do Direito (Essência e Existência). 1ª̂Ed. Rio de Janeiro: Forense, 1964.

JELLINEK, Georg. Teoria General Del Estado. 1를. Buenos Aires: Editorial Albatroz, 1973.

JHERING, Rudolf Von. A Luta pela Direito. 1를. Bauru: Edipro, 2001.

JOHNSON, Samuel. Escritos Políticos. 1를. Madrid: Katz Editora, 2009.

KANT, Immanuel. Analítica do Sublime. Rio de Janeiro: Forense, 1995.

. Critique de La Raison Pure. 7ª̣Ed. Paris: Quadrige PUF, 2008.

. Critique of Pure Reason. 1를. New York: Prometheus Book, 1990.

. Escritos pré-críticos. São Paulo: Editora UNESP, 2005. 
. Fundamentação da Metafísica dos Costumes. São Paulo: Abril

Cultural, 1980.

. Prolegómenos a Toda a Metafísica Futura. 1ª̣d. Lisboa: Ed. 70

Ltda, 2008.

. Textos seletos. 6ªEd. Petrópolis: Vozes, 2005.

- The Cambridge Companion to Kant and Modern Philosophy. 1르. Cambridge: Cambridge University Press, 2007.

KELSEN, Hans. A Justiça e o Direito Natural. 1ª̂Ed. Coimbra: Almedina, 2009.

. O Problema da Justiça. São Paulo: Martins Fontes, 1991.

KUJAWSKI, Gilberto de Mello. Ortega y Gasset. A Aventura da Razão. São Paulo: Moderna, 1994.

LABAND, Paul. Derecho Presupuestario. Trad. José Zamit. Madrid: Instituto de Estudios Fiscales, 1979.

LANG, Jean. Mitos Universais. São Paulo: Landy, 2002.

LANG, Fernando da Silveira. A Teoria do Conhecimento de Kant: O Idealismo Transcendental. Cadernos Cat. Ens. Física, v. 19, número especial: p. 28-51, Instituto de Física - UFRGS. Porto Alegre, 2002. 
LASSALLE, Ferdinand. Que é uma Constituição.2ªEd. São Paulo: Kairós Livraria Editora Ltda, 1985.

LEIBNIZ, G.W. Discurso de metafísica e outros textos. 1르d. São Paulo: Martins Fontes, 2004.

LIMONGI, Fernando. O presidencialismo de coalizão: o dilema institucional brasileiro. In: Dados. 1988.

LOBO TORRES, Ricardo. Normas de Interpretação e Integração do Direito Tributário. 2ªEd. Rio de Janeiro: Forense, 1994.

Tratado de Direito Constitucional Financeiro e Tributário. Vol. I. Constituição Financeira, Sistema Tributário e Estado Fiscal. Rio de Janeiro: Renovar, 2009.

. Curso de Direito Financeiro e Tributário. 19ªEd. Rio de Janeiro:

Renovar, 2013.

LOCKE, John. An Essay Concerning Human Understanding.

LOEWESTEIN, Karl. Teoria de La Constituicion. 2ªEd., Barcelona: Editora Ariel, 1976.

LOPES, Ana Maria D’Ávila. Os Direitos Fundamentais como Limites ao Poder de Legislar. Sérgio Antonio Fabris Ed., 2001. 
MADDICOTT, J. R. Simon de Montfort, Cambridge: Cambridge University Press, 1994.

MAFFETTONE, Sebastiano; VECA, Salvatore. A ideia de justiça de Platão a Rawls. $1^{2}$ End. São Paulo: Martins Fontes, 2005.

MAQUIAVEL, Nicolau. O Príncipe. São Paulo: Jardim dos Livros, 2007.

MARTINS FILHO, José Reinaldo Felipe. O século do outro: uma interface com o século XX. Revista Filosofia Capital. Vol. 6. 12ªEd. Brasília, 2011.

MASCARO, Alysson Leandro. Crítica da Legalidade e do Direito Brasileiro. São Paulo: Quartier Latin, 2003. Estado e Forma Política. Boitempo Editorial, 2013. . Filosofia do Direito e Filosofia Política. São Paulo: Atlas, 2003.

MATURANA, H.R. VARELA, F.J - A Árvore do Conhecimento: as bases biológicas da compreensão humana. Tradução; Humberto Mariotti e Lia Diskin. São Paulo, Pala Athenas, 2001

MAYOS, Gonçal. Modernidade e Racionalidade: Razão Geométrica /versus Razão Dialética. Barcelona: Marcial Pons, 2005.

MAXIMILIANO, Carlos. Hermenêutica e Aplicação do Direito. 18ª̂Ed. Rio de Janeiro: Forense, 2000. 
MELO FRANCO, Afonso Arinos de. PILLA, Raul. Presidencialismo ou Parlamentarismo? 1를. Rio de Janeiro: Ed. José Olympio, 1958.

. Direito Constitucional - Teoria da Constituição. As constituições do Brasil. 1ªEd. Rio de Janeiro: Forense, 1976.

MIRANDA, Pontes de. Democracia, Liberdade, Igualdade. $2^{2}$ Ed. São Paulo: Saraiva, 1979.

. Introducção a Política Scietifica. Rio de Janeiro: Livraria Garnier, 1924.

MONTEIRO, Juliano Ralo. Ativismo Judicial: Um caminho para concretização dos direitos fundamentais. In: Estado de Direito e Ativismo judicial. José Levi Mello do Amaral Júnior (Coord.). São Paulo: Quartier Latin, 2010.

MONTESQUIEU, Charles. O Espírito das Leis. 4E Ed. São Paulo: Saraiva, 1996.

MORIN, EDGAR. Introdução ao Pensamento complexo. Instituto Piaget, Portugal, 1995. Sulina, Porto Alegre, Brasil, 2005.

NEVES, A. Castanheira. A Crise Actual da Filosofia do Direito no Contexto da Crise Global da Filosofia. 1를. Coimbra: Coimbra Editora, 2003.

Digesta. Vol. 1. Coimbra: Coimbra Editora, 1995. 
OLIVEIRA, Regis Fernandes de. HORVATH, Estevão. Manual de Direito Financeiro. 2ª̄Ed. São Paulo: Revista dos Tribunais, 1997.

Curso de Direito Financeiro. 6 ${ }^{\mathrm{a}}$ Ed. rev., atual. e ampl. São Paulo: Revista dos Tribunais, 2014.

. Gastos Públicos. 1Ed. São Paulo: Revista dos Tribunais, 2012.

PALLIERI, G. Balladore. Diritto Costituzionale. 10ªE. Mlano: A. Giuffré Editore, 1972.

PAPACHRISTOS, A.C. La réception des droits privés étrangers comme phénomène de sociologie juridique. Paris: Librarie Générale de Droit et de Jurisprudence, 1975.

PIÇARRA, Nuno. A separação dos Poderes como doutrina e Princípio Constitucional - Um contributo para o estudo das suas origens e evolução. Coimbra: Coimbra Editora, 1989.

PIRES ROSA, André Vicente. Las Omissiones Legislativas y su Control Constitucional. 1ª̊Ed. São Paulo: Renovar, 2006.

PÍTSICA, Nicolau Apóstolo, PÍTSICA, Diogo Nicolau. Introdução à Ciência Jurídica de Hans Kelsen. Florianópolis: Conceito Editorial, 2008.

PLATÃO. A República. 2ª Reimpressão. São Paulo: Edipro, 2001. 
As Leis. 1ªEd. São Paulo: Edipro, 1999.

POPPER, Karl. A Lógica da Pesquisa Científica. 2ªEd. São Paulo: Cultrix, 2013.

PRADO JÚNIOR, Caio. Evolução Política do Brasil e Outros Estudos. $7^{\text {ªE}}$ Ed. Brasília-DF: Ed. Brasiliense, 1971.

RADBRUCH, Gustav. Filosofia do Direito. 2ªEd. São Paulo: Martins Fontes, 2010. Introdução à Ciência do Direito. 1를. São Paulo: Martins Fontes, 1999.

RAMOS, Elival da Silva. Ativismo judicial: parâmetros dogmáticos. São Paulo: Saraiva, 2010.

RAO, Vicente. O Direito e da Vida dos Direitos. 2ª Ed. São Paulo: Resenha Universitária, 1977.

REALE, Miguel. Filosofia do Direito. 4ªEd. São Paulo: Saraiva, 1965. Nova Fase do Direito Moderno. São Paulo: Saraiva, 1990. . Lições preliminares de Direito. 22ª̄Ed. São Paulo: Saraiva, 1995. 
RECASENS SICHES, Luis. Nueva Filosofia de La Interpretacion Del Derecho. 1르d. México: Fondo de Cultura Economica, 1956.

ROMANO, Santi. Principios de Direito Constitucional Geral. 1를., São Paulo: RT, 1977.

ROUSSEAU, Jean-Jaques. As Confissões. São Paulo: Athena.

O Contrato Social e Outros Escritos. 1ª̊Ed. São Paulo:

Cultrix,

. Discursos sobre as Ciências e as Artes e Sobre a Origem da Desigualdade. São Paulo: Athena.

SANTO AGOSTINHO. Sobre a Potencialidade da Alma. De quantitate animae. 2ª̣d. Petrópolis: Vozes, 2005.

SCAFF, Fernando Facury. Constitucionalizando Direitos. $1^{\text {a }}$ Ed. Rio de Janeiro: Renovar, 2003.

SCHMITT, Carl. Teologia Política. Belo Horizonte: Del Rey, 2006. . O Conceito do Político. Petrópolis: Vozes, 1992.

SILVA, José Afonso da. Orçamento-Programa no Brasil. São Paulo: Revista dos Tribunais, 1973. 
SILVA, Sandoval Alves da. Direitos sociais: leis orçamentárias como instrumento de implementação. Curitiba: Juruá Ed., 2007.

SILVA MARTINS, Ives Gandra. (Org.) Direito Financeiro e Tributário Comparado. Estudos em Homenagem a Eusébio Gonzalez Garcia. $1^{\mathfrak{a} E}$ Ed. São Paulo: Saraiva, 2014.

SILVEIRA, Paulo Fernando. Freios e Contrapesos (Checks and Balances). Belo Horizonte: Del Rey, 1999.

SOARES DE PINHO, A. P. Freios e Contrapesos do Governo na Constituição Brasileira. Niterói:, 1961.

SPINOZA, Baruch. Etica. São Paulo: Athena, 1945. . Tratado Político. São Paulo: Cultura Moderna.

STUART MILL, John. La Logica de las Ciencias Morales. 1ªEd. Madrid: Consejo Superior de Investigaciones Cientificas, 2010.

SUPREMO TRIBUNAL FEDERAL. A Constituição e o Supremo. $3^{\text {a }}$ Edição. Brasília: Secretaria de Documentação, 2010.

TAVARES, André Ramos. Curso de Direito Constitucional. 6 ed. ver. e atual. São Paulo: Saraiva, 2008.

TEILHARD DE CHARDIN, Pierre. O Fenômeno Humano. Porto: Tavares Martins, 1970. 


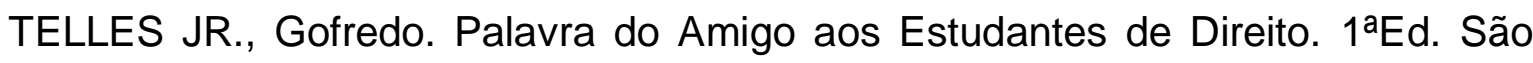
Paulo: Juarez de Oliveira, 2003.

THEIMER, Walter. Historia de las Ideas Politicas. Barcelona: Ediciones Ariel, 1960.

TORRES, Heleno Taveira. Direito Constitucional Financeiro. Teoria da Constituição Financeira. 1ªEd. São Paulo: Editora Revista dos Tribunais, 2014.

UHLMANN, Günter Wilhelm. Teoria Geral dos Sistemas: Do atomismo ao Sistemismo. Versão pré-print. São Paulo, 2002.

UNGER, Roberto Mangabeira. O Direito e o Futuro da Democracia. 1 1ªEd. São Paulo: Bomtempo Editorial, 2004.

VEIGA FILHO, João Pedro da. Manual da Sciencia das Finanças. $2^{2}$ ed. São Paulo: Espíndola \& Companhia, 1906.

VIEIRA, Jorge de Albuquerque Organização e Sistemas São Paulo: PUC SP, 1998

VILANOVA, Lourival. As Estruturas Lógicas e o Sistema do Direito Positivo. São Paulo: Max Limonad, 1997. . Lógica Jurídica. São Paulo: Bushatsky, 1976. 
VILLAS BOAS FILHO, Orlando. O Direito na Teoria dos Sistemas de Niklas Luhmann. 1를. São Paulo: Max Limonad, 2006.

Teoria dos Sistemas e o Direito Brasileiro. $1^{\mathrm{a}} \mathrm{Ed}$.

São Paulo: Saraiva, 2009.

VILLEY, Michel. Filosofia do Direito. Definições e Fins do Direito. São Paulo: Atlas, 1977.

YOLTON, John W. Dicionário Locke. Tradução Álvaro Cabral. Rio de Janeiro: Ed. Jorge Zahad, 1996. 